six months follow-up, in whom I have used loop diathermy in a District General Hospital genitourinary clinic.

All 100 patients had loop diathermy performed only after prior colposcopically controlled biopsy had shown some degree of CIN. The inital pre-treatment colposcopy had been indicatd by the presence of mild dyskaryosis, or worse, on cytology (89 women), cervical warts (7 women), or naked eye clinical suspicion of disease ( 4 women). In all women the upper margin of the transformation zone was colposcopically visible.

The age range was $18-42$ years with a mean of 24 .

Local anaesthesia was provided using $2 \cdot 2 \mathrm{ml}$ of Citanest, infiltrated intra-lesionally using a dental syringe. A Force 2 electro-surgical unit (Valleylab, Boulder, Colorada, USA) was used, in the monopolar mode, with a blended cutting and coagulation output of $40+40$ watts respectively. The transformation zone was resected using Rocket disposable loops of 0.006 " gauge wire leaving a $2-3 \mathrm{~mm}$ margin on all sides. At the end of the procedure the cut surface was further coagulated with a ball electrode, to achieve complete haemostasis. Sultrin cream was then squeezed into the resection area and upper vagina. All 100 patients have now completed at least six months follow-up, and detailed statistical analysis will be reported in a subsequent communication.

Practically, loop diathermy provides a very advantageous and efficacious method of treatment for such genitourinary patients. Histological examination showed the removal of one previously unsuspected adenocarcinoma, 18 CIN III, 47 CIN II, 29 CIN I and five patients in whom only warty or no pathology was identified.

All but three of these removals were considered to be histologically complete, and in those three women subsequent colposcopic examination at 6 months showed no recurrence. (This is probably due to extra tissue damage performed during coagulation).

No patient was admitted for primary haemorrhage. Four women returned with secondary haemorrhage (all associated with anaerobe infection) and only one of these was hospitalised (for 24 hours).

Of the 100 women re-colposcoped after 6 months, five have been shown to have some remaining CIN. (Four CIN I and one CIN II). All were associated with wart virus infection.

None of these patients waited for more than 3 weeks between diagnostic colposcopy and loop diathermy. This compares with a much longer wait for the same procedure organised by local gynaecologists.

Essentially loop diathermy is a safe, effective procedure which can be offered conveniently and quickly to genitourinary patients. It should save morbidity (both mental and physical) as well as time, and thereby be cost effective. Initial questioning reveals it to be very well tolerated by patients who appreciate the speed at which the procedure can be performed.

It should however, be undertaken only by experienced operators, in departments where communication with gynaecological colleagues is productive, and access to resuscitation procedures and a gynaecological bed is immediate.

I shall report more detailed information regarding these patients in due course, but would recommend this procedure to colleagues.

$$
\begin{array}{r}
\text { D A HICKS } \\
\text { Royal Hallamshire Hospital, } \\
\text { Glossop Road, } \\
\text { Sheffield S10 2fF, UK }
\end{array}
$$

\section{Sexually transmitted disease [STD]} control

The Communicable Disease Surveillance Centre's ten year (1981-1990) review of the size and nature of the STD problem in England and Wales is welcome and timely. ${ }^{1}$

The review shows a consistent and cohesive epidemiological picture based on new patient numbers, diagnoses, age, sex and sexual orientation. The role of adolescents, women and homosexuals/bisexuals is detailed. The conclusion is stated unequivocally: "The data emphasise the need for renewed efforts towards prevention and control".

The Committee of Enquiry Report regarding Public Health noted dangerously low levels of control of infectious diseases. ${ }^{2}$ More than a ten year review is needed to show if this applies to STDs. Some of us suspect that it does, and suggest two long term retrospective studies to establish or refute the suggestion as fact or fiction.

The first need is a study of the geography of STDs in the UK. It would no doubt show disparities between districts in terms of cities, towns and suburban areas and even between comparable population densities. Such findings should help evolve markers of service efficiency. New patient numbers per 100000 population, follow-up, incidence of complications and evidence of effectiveness of health education endeavours offer a basis. A detailed geographical study would also help ensure more even-handed deployment of resources and laboratory support. In areas of low prevalence the use of certain laboratory methodologies such as ELISA testing for chlamydia detection may give unaccceptably high false positive test rates.

The annual returns made by genitourinary medicine clinics over the last half century can provide much of the data required for this study. The chances are that the results could lead to improved STD prevention and could help to identify suitable sentinel clinics in which complementary prospective studies could be performed.

The second proposed long term retrospective study concerns the tracing, testing and treating of the sex partners of infected patients. 
Following presentation of a review of the attitudes and actions of genitourinary medicine consultants and health advisers regarding contact tracting, Keenlyside ${ }^{3}$ reported no change in such services over the last 10 years. This is in keeping with our view that contact tracing services in the UK began deteriorating in the early seventies, reached their nadir over 10 years ago and have since operated "at a dangerously low level" of prevention and control. Thus there has been comparatively little on the topic in the literature in the last 20 years.

The results of contact tracing in syphilis and gonorrhoea were reported by the country's 200 clinics for some twenty years. There was never any feedback of the data. Publication of a detailed study of these data seems essential to measure progress. How well or otherwise clinics matched the potential of contact tracing for prevention and control as shown by the "Tyneside Scheme" audited their endeavours 5 , is unknown. Clearly if we are to "renew efforts towards prevention and control" and effect improvements, a base line of this sort would be essential.

A lead by the Disease Surveillance Centre towards the STD's featuring in a future issue of "Health of the Nation" would be a useful early objective.

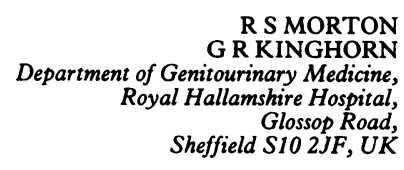

1 Catchpole MA. "STD in England and Wales 1981-9". CDR 1992;2:1-7 [Review Number 1] PHLS CDSC

2 Public Health in England. The Report of the Committee of Enquiry into the Future Development of the Public Health Funnction. HMSO London Cn 189, 1991

3 Keenlyside RA. Partner Notification. Paper read to Medical Society for Study of Venereal Diseases. London. 24 January, 1992.

4 Wigfield AS. " 27 years of uninterrupted contact tracing". The Tyneside Scheme. Br J Venereal Dis 1972;48:37-50.

5 Morton RS. Gonorrhoea. The Control of Gonorrhoea, Chapter 10. 235-282 London. W B Saunders. 1977.

Accepted for publication 6 February 1992

\section{Survey of cervical cytology in Engl- ish genitourinary medicine clinics}

In October 1991, we carried out a postal questionnaire survey of genitourinary medicine clinics in England, to find out their cytology taking and reporting practices. We felt that some of the findings might be of interest in the light of the recently circulated recommendations from the Council of the MSSVD entitled Guidelines on Cervical Cytology, Confidentiality and GUM Clinics.

The response rate to the questionnaire was $131 / 182(72 \%)$, with one spoiled paper, excluded from further analysis. Three questions
Table 1 Q Do you inform the patient's general practitioner of the smear result?

\begin{tabular}{lrrrrr}
\hline & \multicolumn{4}{c}{ Numbers of clinics (total 131) } \\
\cline { 2 - 5 } & Yes & No & $\begin{array}{l}\text { Not } \\
\text { answered }\end{array}$ & $\begin{array}{l}\text { Other } \\
\text { answers }\end{array}$ \\
\hline $\begin{array}{l}\text { i) Routinely } \\
\text { ii) If the smear is abnormal }\end{array}$ & 48 & 82 & 1 & 0 \\
$\begin{array}{l}\text { iii) When replying to a } \\
\text { referral letter }\end{array}$ & 108 & 2 & 21 & 54 & 16 \\
\hline
\end{tabular}

Table $2 Q$ Do you get the patient's permission to inform the GP?

\begin{tabular}{lllll}
\hline & Yes & $\begin{array}{l}\text { Not } \\
\text { always }\end{array}$ & No & $\begin{array}{l}\text { Not } \\
\text { answered }\end{array}$ \\
\hline Numbers of clinics & $117^{\star}$ & 5 & 7 & 2 \\
\hline
\end{tabular}

$\star$ Of these, 50 always obtained written consent.

Table $3 Q$ Information included on request forms accompanying cervical smears

\begin{tabular}{lcl}
\hline Information & $\begin{array}{l}\text { Numbers of } \\
\text { clinics }\end{array}$ & $\begin{array}{l}\text { \% of total } \\
\text { respondents() }\end{array}$ \\
\hline $\begin{array}{l}\text { Clinic. No. only } \\
\text { Clinic No. and other details }\end{array}$ & 62 & $(47)$ \\
$\begin{array}{l}\text { Name on form } \\
(13 \text { volunteered they }\end{array}$ & 63 & $(3)$ \\
$\begin{array}{l}\text { sought consent) } \\
\text { Question not answered }\end{array}$ & 2 & $(48)$ \\
\hline
\end{tabular}

in the questionnaire have relevance to the recent recommendations: these results are summarised in tables 1,2 and 3.

The Council of the MSSVD suggests that all patients are made aware of the option to remain anonymous, but if any abnormality is found, all efforts should be made to obtain the patient's consent to inform the general practitioner (GP) of this (tables 1 and 2). Currently 20 clinics do not inform the GP if a smear is abnormal, and two clinics do not inform the GP of the result even when replying to a referral letter.

The Council of the MSSVD recommends that the initials, year of birth and clinic number only should be used on the request form (in those wishing their visit to remain confidential). The current practices are shown in table 3. It should be noted, however, that we did not ask specifically about using the patient's date of birth.

There exists a wide variety of policies at present; it will be interesting to see how soon changes in practice result from the MSSVD recommendations. We hope to present further data from our survey at a later date.

Thanks are due to all who kindly completed the questionnaire. S M YOUNG S M YOUNG
Department of Genitourinary Medicine, Leicester Royal Infirmary,
Leicester LE1 SWW, UK 